\title{
Onda sinusoidal en el electrocardiograma
}

\section{Sinusoidal wave on the electrocardiogram}

\author{
Mario Andrés Hernández Somerson • Bogotá, D.C. (Colombia)
}

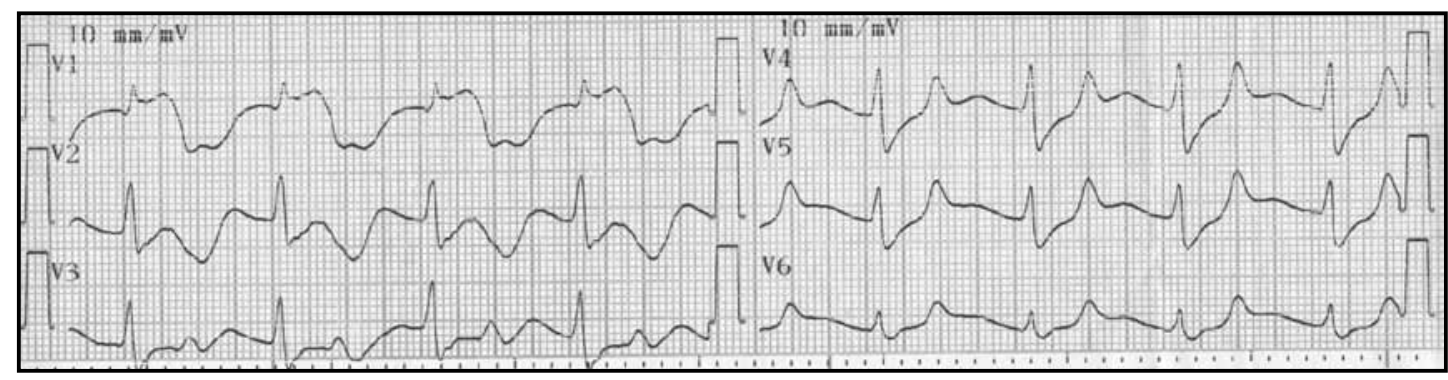

Figura 1.

Electrocardiograma de ingreso.

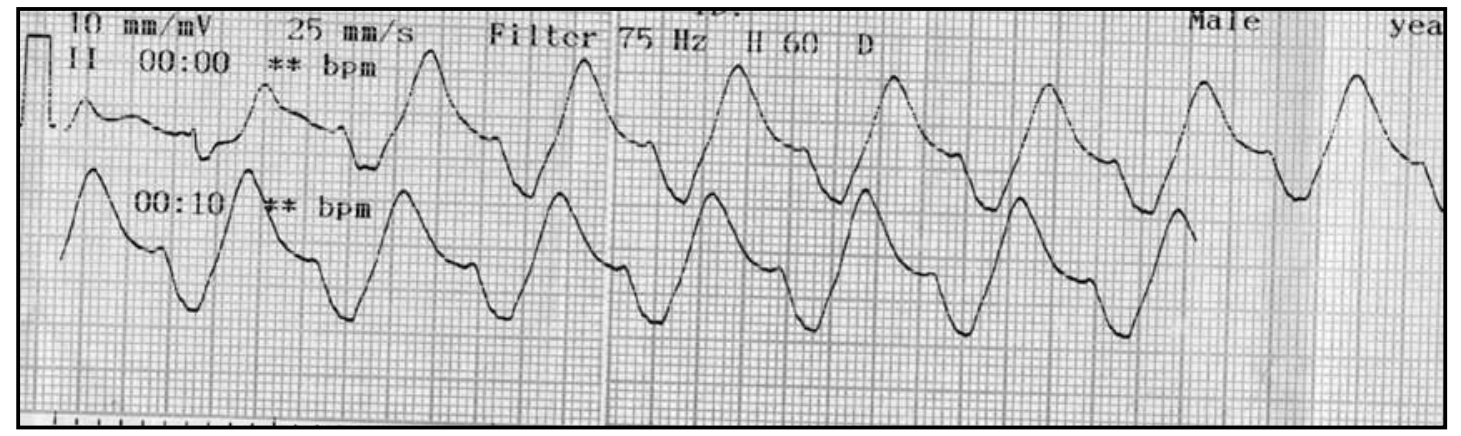

Figura 2.

Electrocardiograma de control tomado a los 10 minutos. Onda sinusoidal.

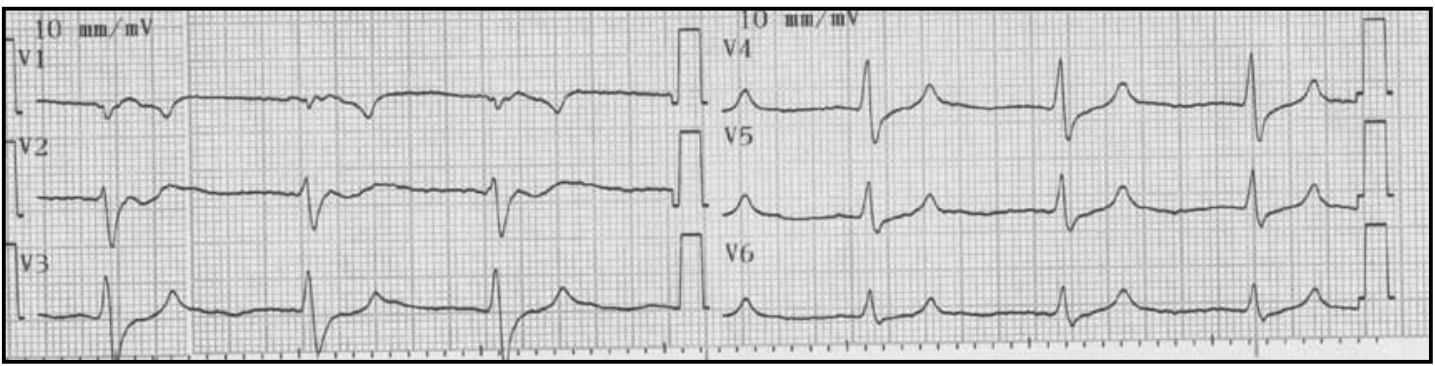

Figura 3.

Electrocardiograma posterior a manejo con gluconato de calcio IV. Reversión de onda sinusoidal.

Mujer de 58 años, con cuadro de una semana de evolución consistente en astenia progresiva, disnea con esfuerzos medianos y en últimas 48 horas somnolencia marcada. No refiere antecedentes de importancia.

A su ingreso con tensión arterial en 90/60, frecuencia cardiaca: 50 por minuto, frecuencia respiratoria 14 por minuto y afebril. Se observa con signos de deshidratación grado II y estuporosa. Se toma glucometría en $95 \mathrm{mg} / \mathrm{dL}$ y electrocardiograma (Figura 1) con evidencia ausencia de onda P con R-R regular y ensanchamiento del complejo QRS (130 mseg), con intervalo QT corregido prolongado (460 mseg) y trastorno inespecífico de la repolarización. Se inicia manejo hídrico, oxigenoterapia, monitoreo electrocardiográfico y se toman paraclínicos. Se realiza electrocardiograma de control a los 10 minutos que muestra la presencia de una onda sinusoidal (Figura 2).

Ante la sospecha de hiperpotasemia, se inicia gluconato de calcio intravenoso a $10 \%, 10 \mathrm{cc}$ cada 10 minutos hasta reversión de la onda sinusoidal (Figura 3), en total requirió 40 cc. Se reciben niveles de potasio en $8.6 \mathrm{meq} / \mathrm{L}$, creatinina en $10 \mathrm{mg} / \mathrm{dL}$ y nitrógeno ureico en $110 \mathrm{mg} / \mathrm{dL}$. Se complementa manejo farmacológico para hiperpotasemia y se interconsulta al servicio de nefrología para inicio de terapia de reemplazo renal urgente.

Palabras clave: onda sinusoidal, hiperpotasemia, intervalo QT prolongado

Key words: sinewave, hyperkalemia, prolonged $Q T$.
Dr. Mario Andrés Hernández Somerson: Internista, Mederi - Hospital Universitario Mayor. Bogotá, D.C. (Colombia).

Correspondencia. Dr. Mario Andrés Hernandez Somerson. Bogotá, D.C. (Colombia).

E-mail: somerson18@hotmail.com Recibido: 10/II/2015 Aceptado: 14/IX/2015 